\title{
To the problem of the past, modern and the future of National academy of agrarian sciences of Ukraine
}

\author{
V. Yurchyshyn, \\ Academician of the NAAS, Doctor of Economic Sciences Presidium of the National Academy of \\ Agrarian Sciences
}

Features of operation of NAAS for 25 years are studied, and key questions of development of the strategy of its further development are justified. It is noted what even under condition of the limiting factors occurred, the Academy managed to be saved from menacing calls and to enrich its scientificcreated potential, including fundamental level. Concerning the future of Academy the necessity of elaboration of the strategy of its development which by its special-purpose designation, nature, character of practical embodiment should meet the requirements and queries of national necessary level is proved. It will enable Academy to execute not only scientifically-providing, but also socially necessary functions in aspect of overcoming destructive aftereffects in agrosphere caused by imperfect state agrarian policy.

Key words: strategy of development, scientific-created potential, national necessary level, trinity of scientific, public and social functions, state agrarian policy.

The purpose of the article is to develop the conceptual foundations of the NAAN development strategy, taking into account the most significant features of functioning in the period since its foundation.

It is justified to start with the optimistic expectations inspired by the return of the Academy to its generic nest. Optimistic even when there are not many reasons for them. And yet they are. Including those that I consider to be key. One of them is the very fact of our return to our home, which is known to always be happy and inspiring. We will console ourselves with the fact that this time will be the same. In this nest we were born, passed the first academic baptism, learned that it is the Academy, who we are in it and what our purpose. We have created conditions under which we were able to fully justify it. We were obedient and loyal to our strategic purpose. Including, to a large extent due to the first president of the Academy Alexei A. Sozinov.

Another reason for optimism is that, despite the well-known periodic difficulties that occured in and around the Academy from time to time, it retained and substantially increased its initial fundamentals scientific and creative potential, including the fundamental level. Another reason for optimism is that she was worthy of being able to stand when she was very hard and hurt for her future. And this power was so powerful that the circumstances in her last time, which are increasingly encouraging, give reason to see in them the contours of its really possible better future and to predict the ways and mechanisms of its provision.

For all this, it would be a mistake not to look back at what was happening in it not only shameful, but destructive. Take a look to evaluate it from time to time in order to prevent a repetition of this in the future. On the first place in it I put what we found to be overwhelming to confront the chief-thief of the state-leading level, one of the founders of oligarchic clans in our country, including agrarian origin, then Prime Minister Pavel Lazarenko, removal from the leadership of the Academy of its first President, an outstanding, worldrenowned geneticist, academician of the National Academy of Sciences of Ukraine, and at the same time academician and first vice president of the famous VASGNIL Alexey Sozinov. Known, besides many other of his best virtues, scientific and civic principles. Such Pavlo Lazarenko did not fit, and he achieved his. I am convinced that under the President O.O. Sozinsky our Academy would be immune from encroachments on its scientific majesty. When it also could not be possible attempts to destroy it in the form of massive attacks on its physical capture. Fortunately, by joint efforts, we managed to protect it from this and start the necessary progressive changes and processes in its development. One of the reflections of such a victory is the return of the Academy to the generic nest.

Of course, this fact alone does not guarantee the revitalizing success that is so necessary to us. Especially in circumstances never before seen in our country, the threats to science in the form of approaching its state funding to, as they say in such cases, there is nowhere, which one of the domestic 
philosophers S. Grabovsky ("Day", February 20, 2016) assessed such state action in relation to the National Academy of Sciences of Ukraine with the shooting of science. He confirmed this by the fact that the murder of science in our country has already become a feasible fact, the consequences of which will be the loss of its scientific potential, scientific schools and scientific fields, and the limitation of the influx of talented young people.

And science, as such, according to its vision, if it stands, will be revived only in decades. Before this, and in many respects, the domestic agrarian science, represented by our Academy, became even more threatened. According to this, we have with you, convinced that no one has succeeded in killing science yet, and this time, there is only one way, the victorious power of which only the most interested in this scientific core of the Academy is strongest: its actual members ( academicians), correspondent members and research teams of research institutions. The tool for this is very simple and at the same time extremely difficult and difficult. Namely: to assume responsibility for the future of the Academy and its agrarian science in all its multidimensional and scale-away from possible disruptions and destructions, to jointly endeavor to enrich and create the creative potential of the practice in its consistent pursuance.

And let's do it wisely, if the basic tool for achieving such a goal is to choose clearly and comprehensively jointly worked out the strategy of the Academy's development.

It is still not possible to predict what the final version of strategic visions might be as a summary of the relevant collective views: general-academic, departmental and research institutions. But it is justified enough to focus on the fact that in each case it should clearly cover, on the one hand, the essence, the final and phased implementation of the purpose of each given strategy, and, on the other hand, - a set of tools and mechanisms for ensuring its scientific and practical implementation and functioning at the nationally necessary level. This approach means that in a directly applied science, each specific strategy will have to fulfill not only the scientifically-supporting, but also socially and socially necessary functions. Only in such a triune of its strategically targeted purposes, it will be a holistic, completed, systematic and real creation phenomenon, again, nationally necessary level.

One of the conceptually important components of the target vision of the future strategy of the Academy's development in this case is also the subordination of its needs to overcome in the country the agrarian and rural-peasant ruins provoked by essentially imperfect and impunity-irresponsible state agrarian policy. Not a reform, as some, or many, continue to believe, namely, all that is now issued by the state agrarian policy, which, if based on its assessment of socio-political and socio-economic performance, is a quasi-policy. As a result of such a policy, the objectively inevitable reformation of the various kinds that took place within its boundaries, instead of being its real building blocks, became her own, politicians, socially and socially disadvantaged victims, in particular, difficult to recover or not, which can not be restored.

Each of them has the right to a personal vision, including the opposite to the one stated. But I continue to defend my views on the fact that we now have a ruin in our own agrarian and rural-rural sectors. This position, together with one of the most prominent domestic economists-agrarians, academician of the National Academy of Sciences of Ukraine Oleksiy Museyovych Onyshchenko, was submitted 10 years ago in the journal "Economics of Ukraine". Since then nobody denied us. At the same time, several books were published, in which the agrarian reform is given exclusively at the angle of praise.

In connection with this author of the article, perhaps, most of all, I would like to have time to complete and see the published monograph, which I am currently working on, and which I intend to publish in coauthorship with the same academician $O$. Onishchenko, which, unfortunately, has been almost 10 years , as he died. And to present it openly and fundamentally as closely as possible to reality, including in part of the discussion-critical vision of what appears to be an agrarian reform in our country after its acquisition of sovereignty. Not only is it necessary but also objectively inevitable socio-political and socio-economic phenomenon of the national level and strategically purposeful purpose, which, having provided to a certain extent conceptually important achievements in the field of land relations, relations of ownership and industrial relations in the countryside, very much which turned out to be contrary to its strategic objectives and their social and social potential. Including, most of all, in its antisillo-peasant part. In the form, on the one hand, of the final destruction of the historically peculiar to the domestic peasantry of the national-genetic way of rural life (the first sinister ruins of this type were laid and occurred in Soviet times). On the other hand, the construction in the agro-sphere and the rural-peasant sector of the country's economy instead of the farmer, 
in its best sense, style, oligarchic-latifundist style (arrangement) with all the known consequences in this regard.

In spite of the fact that in this way a powerful production potential is concentrated and a large share of agricultural production is produced, it, in its present form, is consistently asocial in relation to the village and peasants. In connection with this, agrarian science, primarily its agrarian and economic component, is called upon to make a lot of efforts, including those that will be perceived ambiguously, for its profound transformation in the interests of not only agriculture, villages and peasantry, but also the country as a whole. Despite the fact that not everyone perceives this analogy, I allow myself to compare with a certain convention the oligarchic-latifundist manner with a rock similar to the one that Ivan Franko wrote about the national sculptor: "Roll this rock." This vision has nothing to do with the call for its physical destruction. This exceptionally appeal to those involved in this problem, the scholars and all who have a soul and heart for the preservation of the agrosphere, peasants and peasants from further neglect, humiliation, destruction and destruction, to urgently activate by means of aggregate knowledge, skills, efforts and responsibilities to ensure consistently systemic rebirth to the socially and socially necessary level of the main industrial production of the country and its rural-peasant primary in a clearly defined strategic direction. How it really can happen depends to a large extent on agrarian science, above all on the one that is concentrated in our Academy.

Known intentions of the Presidium and the President of the Academy to organize work on the project of the strategic foundations of its development in such a way that at the end of this year to bring it to a logical conclusion. I see in this personal interest and responsibility before the high name of the Academy, whose actual member I have the honor to be from the day it was founded. The pain for her future constantly accompanies me. I'm in front of her in a lifetime duty. 